\title{
Encontro com meninos Infâncias como potência
}

VIrGínia LOUZADA* AndRÉa Ribeiro**

\begin{abstract}
RESUMO: Este artigo propõe uma reflexão sobre a potência infantil, a partir da observação de duas crianças consideradas especiais numa creche escola situada à Zona Norte do Rio de Janeiro. O encontro com elas permitiu às autoras do texto desconstruir conceitos preestabelecidos sobre infância, aprendizagem, educação e escola. A discussão privilegia a educação inclusiva e a avaliação. $\mathrm{O}$ artigo defende a necessidade de se enxergar as crianças de modo afirmativo, por sua potência, e a importância da reflexão constante dos educadores sobre a prática pedagógica.
\end{abstract}

Palavras-chave: Crianças especiais. Infâncias. Inclusão infantil. Avaliação.

\section{Meeting with boys Childhood as power}

\begin{abstract}
This article proposes a reflection about the power of the child, from the observation of two children considered special in a day care school situated in the North Zone of Rio de Janeiro. The meeting with them allowed the authors of the text to deconstruct pre-established concepts about childhood, learning, education and school. The discussion focuses on inclusive education and evaluation. The article defends the need to see the children in an affirmative
\end{abstract}

* Doutora em Educação pela Universidade Federal Fluminense. É Professora da Faculdade de Educação da Universidade do Estado do Rio de Janeiro (UERJ). Participa do Grupo de Pesquisa "Currículos, redes educativas e imagens" e é pesquisadora colaboradora do Grupo de Estudos e Pesquisas sobre Avaliação na Escola Pública (GEPAEP). Rio de Janeiro/RJ - Brasil. E-mail: <virginialouzada.feuerj@gmail.com>.

** Graduanda em Pedagogia da Universidade do Estado do Rio de Janeiro, mesma instituição onde também se graduou em Letras. É especialista em Literatura Brasileira e membro do grupo de pesquisa "Formação de educadores e práticas pedagógicas com bebês de zero a dois anos" da UERJ. Rio de Janeiro/RJ - Brasil. E-mail:<dearibeiro@gmail.com>. 
way, in its own powerful way, and the importance of constant reflection by educators on pedagogical practice.

Keywords: Special children. Childhood. Child inclusion. Evaluation.

\section{Encuentro con niños}

La infancia como potencia

RESUMEN: Este artículo propone una reflexión sobre la potencia infantil, a partir de la observación de dos niños considerados especiales en una guardería escuela situada en la Zona Norte de Río de Janeiro. El encuentro con ellos les permitió a las autoras del texto deconstruir algunos conceptos preestablecidos sobre infancia, aprendizaje, educación y escuela. La discusión privilegia la educación inclusiva y la evaluación. El artículo defiende la necesidad de ver a los niños de manera afirmativa, por su potencia, y la importancia de la reflexión constante de los educadores sobre la práctica pedagógica.

Palabras clave: Niños especiales. Infancia. Inclusión infantil. Evaluación.

\section{Rencontre avec des enfants}

Les enfances comme puissances

RÉSUMÉ: Cet article propose une réflexion sur la puissance infantile, à partir de l'observation de deux enfants considerés comme en situation de handicap, dans une crèche-école située dans la zone nord de Rio de Janeiro. Cette rencontre a permis aux auteurs de ce texte de déconstruire des concepts pré-établis sur l'enfance, l'apprentissage, l'éducation et l'école. Notre discussion privilégie l'éducation inclusive et l'évaluation. L'article défend la necessité d'envisager les enfants de manière affirmative, du fait de leur puissance, et l'importance d'une réflexion constante des éducateurs sur la pratique pédagogique.

Mots-clés: Enfants en situation de handicap. Enfance. Inclusion infantile. évaluation. 


\title{
Considerações iniciais
}

\begin{abstract}
Esse dia não é um a mais na vida de Simón Rodríguez. [...] O que o preocupa não é mais o mesmo. Mudam algumas das suas perguntas habituais. Surgem novas questões. Uma preocupação se instala nele, em seu corpo, em sua maneira de ver o mundo. [...] Thomas permite um movimento incomum e extraordinário na vida de Simón Rodríguez. A partir desse dia, nada será como antes: alguns dos princípios que o acompanharão pelo resto de sua vida já tomaram corpo, saíram de um corpo e entraram em outro e, nele, seguirão viajando para sensibilizar outros corpos [...].
\end{abstract}

(KOHAN, 2013, p. 32, 35)

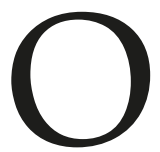

texto desta epígrafe faz parte do livro O mestre inventor, mais especificamente do capítulo "A história de Thomas", em que Kohan (2013) narra o encontro do educador Simón Rodríguez com o pequeno Thomas. Sempre que saíam da escola, Simón Rodríguez e seus alunos iam brincando pelas ruas, jogando para cima seu chapéu. Um dia, Rodríguez acertou o chapéu no vaso da varanda de uma casa cujos moradores já haviam reclamado da algazarra do grupo. Como, então, poderiam pegá-lo de volta?

As crianças fizeram sugestões: utilizar o galho de uma árvore ou tocar a campainha da casa. Ambas eram impraticáveis. A primeira, porque os galhos disponíveis eram muito fracos para suportar o peso de qualquer uma das crianças; e, a segunda, porque os donos da casa já haviam demonstrado antipatia pelo grupo. Então, de repente, Thomas sugere que as crianças subam nos ombros de Rodríguez e todos construam uma escada humana. Rodríguez aceita a ideia de Thomas, coloca-o na ponta da escada, ou seja, como aquele que pega o chapéu, e, assim, o problema é resolvido. Desse encontro em que o menino propõe ao educador uma forma inusitada de solucionar um problema advém a Simón Rodríguez um verdadeiro "terremoto interior" (p. 32). Extasiado com a atitude do menino, ele se pergunta como nunca havia pensado naquilo antes e, a partir daí, passa a pensar a si mesmo, a Thomas e a escola como nunca havia pensado.

Algo semelhante nos aconteceu e decidimos começar este artigo assim. Trabalhamos com o relato de experiências vivenciadas por uma das autoras deste texto com duas crianças consideradas especiais em uma creche escola da rede particular de ensino situada à Zona Norte do Rio de Janeiro. As experiências propiciaram as reflexões necessárias para esta escrita.

Por acreditar que toda prática pedagógica se baseia em determinadas concepções - de escola, de criança, de infância, de aprendizagem, de desenvolvimento, de educação -, precisamos começar elucidando qual é a nossa concepção de infância. Sarmento, com base na sociologia da infância ${ }^{1}$, nos ajuda a entender que a infância é uma construção social feita por sujeitos historicamente situados e definida a partir dos limites etários arbitrários, impostos às crianças, de representações sociais, crenças, dispositivos de socialização e controle que a instituíram como esta categoria social própria, desde os séculos XII e XIII. 
[...] categoria social constituída por actores sociais de pleno direito, ainda que com características específicas (SARMENTO, 1997, p. 11). [...] não como menores ou como componentes acessórios ou meios da sociedade dos adultos. (SARMENTO, 1997, p. 20)

Mais do que silenciadas e ignoradas, as crianças têm sido marginalizadas e "menorizadas" (QVORTRUP, 1995), pois o poder de controle dos adultos sobre elas está reconhecido e legitimado, e as coloca em uma posição subalterna em relação a eles, independentemente de seu contexto social ou histórico. Para Sarmento (Idem), a existência de um grupo socialmente subalterno devido a sua condição etária é essencial à definição da infância. Historicamente, essa categoria etária foi constituída como diferença geradora da desigualdade. Ainda para Sarmento (2005), um traço característico da infância é a perspectiva da negatividade que acompanha desde a palavra latina in-fans ${ }^{2}$ e se perpetua em outros momentos históricos: a idade da não razão, do não-trabalho. Neste sentido, tem sido percebida por sua ausência e incompletude.

O grande desafio diante de nós é pensar a infância a partir de outra epistemologia, principalmente por causa dessa construção moderna ${ }^{3}$, que enxerga a infância a partir da ausência, do silêncio. Kohan (2007, p. 31) propõe pensar a infância a partir da lógica da presença, de "outras afirmações além da negação de não ser adultícia", de olhá-la a partir dela mesma. Para o autor (idem), o mais apropriado é utilizar a referência das infâncias, das afirmações singulares e plurais.

Torna-se mais do que necessário pensar essas infâncias pela presença, olhá-las por elas mesmas. Isso demanda de nós um compromisso ético e político e um giro epistemológico, pois significa olhá-las a partir do que elas têm; de entendê-las "como presença, e não como ausência; como afirmação, e não como negação, como força, e não como incapacidade." (KOHAN, 2007, p. 101 - grifos do autor).

Com base nesses pressupostos, objetivamos olhar para as crianças consideradas especiais, observando sua capacidade e não suas faltas; procuramos enxergar as possibilidades que esses meninos têm, em vez de reforçar-lhes a ausência de conhecimento. Assumimos o desafio de não compará-los com as crianças consideradas normais, procurando entender os caminhos percorridos por eles em sua singularidade e potência. Entendemos que a perspectiva da normalidade se constitui como negação do direto de todos à aprendizagem.

\section{Encontrando Vicente e Felipe ${ }^{4}$}

Aquela seria mais uma tarde de estágio de observação, obrigatório para a formação em Pedagogia. A instituição escolhida para realizá-lo foi uma creche escola da rede particular de ensino situada à Zona Norte do Rio de Janeiro, que atende a crianças de 
classe média e classe média alta. Uma de nós já tinha passado uma tarde na turma de maternal II (crianças de 3 a 4 anos), mas antes de se fixar nela havia visitado as outras turmas da creche (berçário, maternal, pré). Logo, entre a primeira visita à turma e o estágio contínuo, houve um intervalo de pouco mais de um mês. Na primeira visita ao lugar, nenhuma criança em especial havia chamado atenção, mas, sim, aspectos do cotidiano escolar, como as relações travadas entre a professora e as auxiliares, entre a professora e/ou as auxiliares e as crianças e as das crianças entre si -, as atividades desenvolvidas, os materiais utilizados e a organização do tempo e do espaço. Foi no segundo momento de visitação a essa turma, em cinco dias consecutivos, que o olhar mudou de foco, em virtude de um encontro muito especial.

No terceiro dia em sala, uma de nós conheceu o Vicente, um menino de três anos, que, ao que tudo indica - conforme dito pela psicóloga da creche -, é autista (seu diagnóstico ainda não havia sido fechado naquele momento).

Nos dias anteriores, a pessoa em questão passava a manhã na creche e ia embora entre 11:30h e 12:00h, pois nesse horário as crianças dormiam. Neste dia, porém, quis ficar mais, pois Vicente não parava quieto um só minuto. Seu desejo era ver como lidar com a situação - ele andando de um lado para o outro sem parar, enquanto as outras crianças dormiam.

Antes da "hora do sono", o comportamento de Vicente já tinha despertado sua atenção. Ele não interagia com as outras crianças; jogava-se no chão frequentemente, chorando às vezes; batia nos amigos; gritava de repente em alguns momentos. Intuitivamente, começou a tecer ponderações sobre aquilo: seria ele muito agressivo? O que estaria por trás da agressividade?

Enquanto pensava nessas questões, lembrou-se da literatura acerca do desenvolvimento infantil que, ao considerar o acolhimento das crianças, destacava que, quanto mais agressiva uma criança é, mais amor deve receber (WINNICOTT apud LUZ, 2008). Provavelmente, a agressividade não seria gratuita e poderia acontecer em decorrência de alguma situação que a criança estivesse vivendo; portanto, as manifestações dessa criança precisavam ser compreendidas, amparadas, acolhidas, e não repreendidas. Essa agressividade podia ser um modo de a criança expressar o que ainda não conseguia verbalizar com clareza. Assim, ao observar Vicente, a melhor opção seria dar-lhe o máximo de amor possível.

Nesse ínterim, uma cena muito importante foi presenciada. Vicente gritou, jogou-se no chão e começou a chorar. Imediatamente, uma das auxiliares o acolheu. Pegou-o no colo e o acalentou, dizendo: "Vem cá, meu amor". Em pouco tempo, ele se acalmou e parou de chorar.

$\mathrm{Na}$ "hora do sono", vendo a movimentação de uma das crianças, Vicente começou a se chegar também. Sempre que se jogava no colo de uma das autoras do texto, a criança recebia um abraço; sempre que lhe batia, ela pegava sua mão e dizia calmamente 
"Assim machuca. É devagar, ó, carinho, assim", e fazia com ele o gesto de carinho em seu rosto ou cabelo, quando ele o puxava. Essa atitude era repetida incessantemente.

Em certo momento, Vicente acordou Ingrid, ao bater nela 5 . Depois, Ângela acordou e ele bateu nela também, algumas vezes. Toda vez que isso acontecia, ele ouvia que não podia bater nos amigos, mas, sim, fazer carinho, e uma de nós passava a mão dele no rosto das amigas, dizendo: “Carinho, ó". O interessante aqui, porém, não foi isso, mas a atitude das próprias crianças em relação a Vicente. Ao ser acordada, Ingrid não reclamou, apenas disse: "Eu acho que o Vicente quer brincar". E, quando ele bateu nela, ela a abraçou repetidamente, dizendo "Carinho, Vicente". Ele correspondeu bastante aos abraços dela! Depois, voltou a bater. Ângela também não reclamou com o amigo, nem revidou, apenas disse que ele havia the batido.

O turno da tarde começou - houve a recepção das crianças, a chamadinha -, e uma de nós decidiu ficar mais um pouco na creche para ver a atividade sobre o Curupira ${ }^{6}$ que a professora desenvolveria com a turma. Foi quando essa atividade terminou que viveu o referido encontro. Ela estava sentada no chão, encostada na parede, e Vicente veio correndo, espontaneamente, e se jogou em seu colo! Ela o abraçou longamente e depois o menino começou a embaralhar o cabelo dela, tampando com ele os olhos dela. A pessoa em questão começou a brincar com ele, dizendo: "Ih! Cadê o Vicente? Cadê?". Quando ele tirava o cabelo dela dos olhos, dizia: "Achei! Achei!”. Ele ria muito e dizia: "Achei!". Ele ficou indo e vindo várias vezes e ficaram repetindo a brincadeira. Foi um momento extremamente feliz! Feliz por ele ter vindo em sua direção, pois ela imaginou que tenha se sentido acolhido de algum modo. Mas, sobretudo, por ele ter entendido a brincadeira; ou seja, ele conseguiu estabelecer uma comunicação ali! A brincadeira só foi interrompida quando a professora de inglês chegou.

No dia consecutivo a esse, a autora em questão não foi à creche, mas no seguinte retornou ansiosa para saber como seria o reencontro. Conseguiria Vicente ter a memória de que já haviam se conhecido e brincado?

Quando chegou à creche, a turma estava em aula de inglês, no pátio. Sentou-se um pouco afastada das crianças e algumas vieram lhe abraçar. Vicente permaneceu andando pelo pátio. No decorrer da tarde, sua atenção estava direcionada para ele, é fato, mas não forçou qualquer aproximação, pois não queria guiar seus movimentos, queria que ele agisse espontaneamente. O menino se aproximou dela algumas vezes, ela o abraçava, brincavam (repetindo a brincadeira do dia anterior), de forma "natural".

Interagiram bastante na hora em que as crianças foram brincar com as "novidades" trazidas de casa. Ele gostou muito do carrinho azul trazido por Gabriel. Tanto que o tomava várias vezes das mãos do colega e ficava um bom tempo com ele. A educadora em questão não falava nada quando isso acontecia, pois ficava imaginando que ele não saberia lidar com o "não", choraria e ficaria triste. Tal decisão causou certo incômodo em Gabriel, que ficava vendo Vicente brincar com o seu carrinho e num momento 
sinalizou que estava sem brinquedo. Gabriel foi direcionado para uma mesa onde outras crianças estavam brincando com outros brinquedos, para que ele interagisse com elas e compartilhasse das novidades.

O certo seria dizer a Vicente que o brinquedo era do Gabriel e ter pedido que ele o devolvesse? Deveria ter sido sugerido que brincassem juntos? Mas conseguiria o Vicente brincar junto com Gabriel?

De fato, olhar para Vicente a partir do lugar de "criança autista" que tem dificuldade em interagir com as demais crianças impossibilitou descobrir como ele teria agido na ausência do brinquedo. Por acreditar que o menino não reagiria bem a essa situação, perdeu-se a possibilidade de deixá-lo decidir o que fazer e de pensar coletivamente sobre a questão, inclusive intervindo, caso necessário.

Essas e várias outras questões invadiram nossas reflexões, a partir do encontro com Vicente. Inspiradas em Kohan, consideramos que Vicente possibilitou à colega que teve contato com ele uma série de questões sobre as quais não pensava antes, assim como Thomas o fez com Simón Rodríguez. A primeira delas foi a comunicação. Era necessário descobrir maneiras de se comunicar com ele! Mas, como seria possível se comunicar com ele e com qualquer outro/a aluno/a autista que cruzasse o caminho? Conforme afirma Glat (2009, p. 9), os professores não desenvolvem, "em sua formação inicial, competências para lidar com a diversidade do alunado hoje presente em nossas escolas". Isso significa que muitas vezes é necessário aprender com as próprias situações cotidianas, ter escuta e olhar sensíveis para enxergar e ouvir além do óbvio.

Inevitavelmente, o encontro com Vicente nos levou a pensar muito mais, também, sobre a educação inclusiva. Como promovê-la efetivamente, de modo que seja oferecido a todos os estudantes o acesso aos mesmos espaços e às mesmas possibilidades de aprendizagem? Para isso, precisamos considerar muitos aspectos, como a adaptação curricular, a acessibilidade, a infraestrutura das instituições de ensino, suas concepções de educação e a própria formação de professores, mas o que Vicente mostrou ser o mais importante é que precisamos olhar, sempre, a criança, e não sua deficiência. Vicente não é apenas um menino autista ${ }^{7}$, é, antes de tudo, uma criança. Não é o autismo que o define, nem muito menos o que pode rotulá-lo ou limitá-lo; embora, certamente, devamos conhecer as implicações do autismo em seu desenvolvimento para que possamos oferecer as melhores condições e possibilidades.

Enfim, Vicente nos ajuda a estar mais atentas à realidade, escolar ou não, de pessoas com deficiências. Na creche, foi observado o trabalho primoroso da professora de Vicente em prol de sua inclusão igualitária na turma, tanto que os outros alunos não demonstravam qualquer preconceito ou atitude repulsiva para com ele; ao contrário, todos eram muito afetuosos. Infelizmente, sabemos que essa não é a realidade de todas as escolas. Enquanto uma de nós realizava esse estágio, ouviu o relato de uma colega de faculdade que, em outra instituição, viu uma professora que tinha em sala um aluno 
autista ordenar que as demais crianças da turma o ignorassem. Assim foi feito e o menino passava seus dias dentro da escola, mas totalmente excluído.

Logo depois de ter vivido essa experiência com o Vicente, uma de nós conheceu outra criança que muito a afetou, o Felipe. Achamos mesmo que o termo "afetar" é o mais adequado nessa situação, no sentido de que essas crianças mobilizaram seus afetos, transformaram sua concepção de escola e educação e atravessaram sua existência, assim como Thomas havia feito com Simón Rodríguez.

Felipe, que tinha Síndrome de Down, era aluno do primeiro ano do ensino fundamental, na mesma creche escola de Vicente. Depois do que havia sido experenciado com Vicente, o olhar para o Felipe, de 7 anos, também foi ampliado, para observar as relações travadas entre ele e as demais crianças, professoras e auxiliares dentro da escola e como se dava sua inclusão.

A aproximação com Felipe foi imediata. Ele era bastante afetuoso, adorava ouvir e contar histórias. Uma vez, uma de nós estava lendo uma história que tinha vários animais e, à medida que as imagens apareciam, Felipe ia dizendo seus nomes, como "macaco", "gato", "cachorro". Em determinada página, havia um tamanduá e, ao lado dele, um bicho verde, que ela não sabia dizer o que era. Ao ler, apontou para o tamanduá e disse "tamanduá" e fez o mesmo para o bicho verde, dizendo que também era um "tamanduá". Felipe imediatamente corrigiu a pessoa, dizendo: "Não, tamanduá esse", ao apontar apenas para o tamanduá, e não para o bicho verde. Isso demonstrou sua competência em entender o que estava sendo lido e nos levou a questionar se a capacidade de compreensão do menino não estava subestimada, ao se considerar que ele não estaria entendendo, uma armadilha em que nós educadores podemos facilmente cair, daí a necessidade de reiterar constantemente nossa "crença" na criança capaz. Especificamente no caso das crianças especiais, é importante que não a recebamos com olhar predeterminado, estigmatizado por sua deficiência; é ela que deve nos dizer aonde pode chegar, e não nós.

No que se refere à inclusão de Felipe, foi observado que o menino era bastante querido pelos colegas, que o abraçavam, beijavam e brincavam com ele cotidianamente. Em relação ao ensino, sua professora mostrou o plano de curso desenvolvido especificamente para ele. Sua alfabetização, por exemplo, seguia a sugestão da fonoaudióloga e, por isso, seria empregado com ele o método silábico, diferentemente da turma, que aprenderia por meio de textos. Em conversa com a professora, ela afirmou que tudo deveria ser feito "no ritmo dele". Contou, por exemplo, que, ao retornar das duas semanas de férias, ele havia "esquecido tudo". Então, ela teve de voltar com ele aos conteúdos já trabalhados.

Um episódio importante ocorreu numa aula de educação física. As crianças eram escaladas pelo professor para jogar câmbio. Enquanto o professor formava os dois times, a auxiliar de turma virou-se para o Felipe e disse: "Você senta aqui comigo", levando-o para o canto do pátio. Rapidamente, porém, o professor disse: “Felipe, entra nesse time 
aqui". Felipe levantou-se e jogou com as demais crianças, tendo seus pontos comemorados, como os de todas elas.

Aqui vemos que o professor agiu de forma completamente inclusiva, possibilitando que Felipe participasse plenamente da atividade proposta. Afinal, por que ele não deveria jogar? A fala da auxiliar pode ter incorrido numa postura de subestimação a Felipe ou de superproteção. No entanto, ao considerar Felipe capaz de brincar como os demais alunos, o professor - que dava as instruções do jogo, orientava as jogadas e valorizava os acertos - proporcionou a ele e a toda a turma uma situação de aprendizagem em que todos puderam desenvolver não só os "conteúdos" propiciados pelo jogo - como coordenação motora, equilíbrio, força, estratégia, lógica, percepção espacial -, mas, também, as relações interpessoais e a interação social. Ou seja, nem subestimar nem proteger e possibilitaram ao menino desenvolver seu potencial de aprendizagem, dentro de suas possibilidades.

Para Silva (2000, p. 83), normalizar significa "eleger - arbitrariamente - uma identidade específica como parâmetro em relação ao qual as outras identidades são avaliadas e hierarquizadas". Explicando melhor, atribuímos todas as características positivas à identidade escolhida como norma, enquanto as demais identidades são avaliadas de forma negativa e inferior. Neste sentido, consideramos ser necessário pensar outras formas de avaliar as crianças consideradas "especiais", para além da norma ou do padrão de normalidade.

\section{Vicente e Felipe: como avaliar?}

Uma das inquietações que surgiram a partir dessas experiências diz respeito à avaliação escolar de crianças com deficiências. É certo que na educação infantil não há notas ou conceitos, embora avaliemos os alunos diariamente a fim de observar seu desenvolvimento e favorecê-lo. Mas e no ensino fundamental? Como atribuir uma nota a uma criança especial, num processo que considere suas possibilidades e habilidades, e não a estigmatize nem a desvalorize?

Um pouco mais de um mês depois do estágio na turma de Vicente ter terminado, a educadora que o havia conhecido voltou à creche, para continuar observando o cotidiano da turma. Dessa vez, seu olhar estava bastante focado nele. Pôde-se perceber que, nesse pouco tempo de ausência, ele havia desenvolvido muito! Já no primeiro dia de visita, Vicente interagiu com a educadora por diversos momentos, rindo, brincando e jogando-se em seu colo. Além disso, não estava mais batendo nas crianças, mas, ao contrário, abraçando-as. Em uma tarde inteira, só uma vez ele se jogou no chão. Sua concentração nas aulas também estava bem melhor. Na de educação ambiental, por exemplo, em que o professor levou um sapo e larvas de besouro, ele conseguiu ficar certo tempo atento ao que estava acontecendo e até fez carinho no sapo, quando solicitado. Em atividade 
com a professora regente, fez uma colagem inspirada na história Cachinhos de ouro. Sua linguagem também estava bem mais desenvolvida e ele já estava falando bem mais; anteriormente, dizia palavras isoladas, agora ensaiava frases. Consideramos que todos esses progressos deveriam ser registrados, a fim de materializá-los. Tais registros também poderiam ser utilizados pelos/as professores/as do menino para repensar as próprias práticas pedagógicas e o melhor encaminhamento para possibilitar aprendizagem efetiva.

Quanto a Felipe, após o final do estágio no ensino fundamental, não houve mais contato com ele, pois não foi possível retornar à turma. Contudo, cabe pensar sobre como pode se dar a avaliação de crianças especiais nessa fase da educação básica. Podemos encontrar dois caminhos: o plano educacional especializado (PEI) e as adaptações curriculares. O PEI consiste num plano de ensino feito especificamente para cada aluno, considerando suas necessidades educacionais especiais (NEE), suas possibilidades e potencialidades. Além disso, estabelece objetivos reais, que possam ser alcançados pelo aluno, e considera seu desenvolvimento global. Portanto, considera que "a resposta educativa mais adequada é sempre individualizada" (Dias et al., 2009, p. 109). Já as adaptações dizem respeito ao que se pode fazer para que o aluno consiga realizar a avaliação proposta de modo a ter suas NEE atendidas. Para os alunos com baixa visão, por exemplo, pode-se oferecer material com as letras ampliadas; para os cegos, material em braile ou softwares ledores de tela; para os surdos alfabetizados em Libras como primeira língua, considerar que sua expressão linguística não é a mesma dos ouvintes alfabetizados em Língua Portuguesa e, então, sua escrita possui coerência própria; para os deficientes intelectuais, posicioná-los em locais com menos estímulos visuais e auditivos, em caso de realização de provas, pois se distraem mais facilmente.

Ademais, cabe lembrar, conforme Fontes et al. (2009), que é importante sempre considerar as hipóteses apresentadas pelos/as alunos/as para a resposta dada, pois o que pode parecer ilógico a princípio pode fazer sentido na lógica estabelecida por eles/ as na construção de seu conhecimento. Assim, flexibiliza-se a noção de erro, que passa a ser encarado como um passo a mais no processo de aprendizagem. Segundo as autoras, na avaliação de alunos especiais, sejam suas NEE quais forem,

[...] a noção de erro deve ganhar uma releitura. O erro é a indicação do caminho a ser revisto para ser novamente percorrido. A avaliação deve, assim, se libertar das amarras que classificam os alunos entre bons e ruins e avançar no sentido de redirecionar o processo de ensino-aprendizagem. [...] Ela deve ser processual, contínua e indicar o caminho a ser percorrido para se alcançar o conhecimento que ainda não foi construído pelo aluno (pp. 93-4, grifos das autoras).

Crianças como Vicente e Felipe nos desafiam a olhá-las para além do rótulo de "especial", se é nossa intenção enxergá-las em sua potência. Elas radicalizam o conceito de infâncias, pois padrões universais de criança, aprendizagem e desenvolvimento servirão 
apenas para limitar suas possibilidades. Portanto, elas nos convidam a olhá-las por elas mesmas, sem compará-las com as demais crianças ou com padrões preestabelecidos.

Vicente e Felipe nos oferecem a necessidade de pensar processos avaliativos diferenciados dos que podemos encontrar no cotidiano das escolas. Comumente, "a avaliação é feita comparando o que a criança produz ao que seria esperado que ela produzisse em cada faixa etária" (ESTEBAN, 1993, p. 30). Partir do pressuposto da normalidade, ou seja, de um padrão universal de infância, automaticamente exclui quem é considerado diferente do padrão. Outras infâncias vão vivendo um processo de silenciamento e, mais, de desvalorização ou despotência, inclusive com a naturalização de um discurso que afirma a diferença como sinônimo de deficiência.

Crianças com deficiências agudizam essa lógica. Logo, se a criança não aprende, é por sua inteira responsabilidade, e não se discute a incapacidade de a escola incorporar outras lógicas ao trabalho pedagógico realizado cotidianamente com elas. "Todo conhecimento construído e revelado pelas crianças é desconsiderado e reduzido, a fim de ser submetido a um padrão capaz de compará-las e hierarquizá-las" (ESTEBAN, 1993, p. 27). Neste sentido, a autora (idem) propõe outra possibilidade de avaliação, com a função de ser o indicador de caminhos a serem seguidos, a partir da reflexão docente da própria prática, para entender os caminhos percorridos pelas aprendizagens infantis. Através dessa perspectiva de avaliação, buscam-se entender os movimentos, as direções, os conhecimentos já consolidados e os que ainda estão se estruturando, assumindo-se a busca por uma avaliação para as aprendizagens dos/as alunos/as.

\section{Considerações finais}

A ideia de criança capaz não é nova, mas traz um grande desafio à educação. Considerar a criança como sujeito de direitos, desejos e competências implica delinear uma prática pedagógica em que suas manifestações tenham espaço, em que seu jeito próprio de ser, conhecer, interagir e produzir cultura seja reconhecido e valorizado pela escola, e não silenciado ou domesticado por uma lógica adultocêntrica, que enxerga a criança como um vir a ser.

Em nossa observação acerca de Vicente e Felipe, este foi o intuito: olhar esses meninos pelo que eles eram, por suas potencialidades e possibilidades, e não pelo que lhes faltava. Tentamos enxergar neles, prioritariamente, as crianças que eram, e não suas deficiências. Isso se revelou um desafio para nós mesmas, e às vezes derrapamos, como no momento em que não pedimos a Vicente que devolvesse o carrinho de Gabriel por considerar que ele não conseguiria lidar com essa situação. Ou a surpresa que nos acometeu quando o menino foi capaz de estabelecer comunicação com uma de nós. Provavelmente, aqui, olhamos primeiro para as poucas informações que temos sobre sua deficiência, 
justamente o que nos propusemos a não fazer. Todavia, é preciso considerar que estamos também nós mesmas desconstruindo nossos estereótipos e conceitos previamente construídos; e essa desconstrução só é possível por meio da reflexão diária sobre nossa prática. É essa reflexão que nos permite trilhar novos caminhos e fazer escolhas mais condizentes com o que acreditamos. Por isso, entendemos ser extremamente necessário estudar um pouco mais sobre o assunto, partindo dos desafios que o cotidiano nos apresentou a partir do convívio com esses meninos.

Vicente nos permitiu refletir sobre muitas questões além dele mesmo - como a própria concepção de infância capaz, compartilhada pela sociologia da infância, a inclusão de crianças consideradas especiais no espaço escolar e o modo como pode se dar a avaliação dessas crianças. Muitas dessas questões não eram pensadas por nós antes do encontro com essa criança e por isso Vicente foi para nós o que Thomas foi para Simón Rodríguez. A partir de Vicente, nosso olhar acerca de todas essas questões se expandiu e, por isso, nosso encontro posterior com Felipe pôde ser ainda mais enriquecido. Assim, confirmamos a competência desses meninos em nos afetar e, consequentemente, afetar também o nosso entorno.

Recebido em 07/08/2016 e aprovado em 12/09/2016

\section{Notas}

1 “(...) ao estudar a infância, não é apenas com as crianças que a disciplina se ocupa: é, com efeito, a totalidade da realidade social o que ocupa a Sociologia da Infância". (SARMENTO, 2009, p. 19)

2 O que não fala.

3 "A ideia de que a criança tem especificidade é uma construção da modernidade". (QVORTRUP, 1995, p. 138). Este fato é explorado por Àries (1979).

4 Os nomes são fictícios, para preservar o anonimato das crianças.

5 Os nomes das demais crianças também são fictícios pelo mesmo motivo.

6 Naquele momento, a escola estava trabalhando o projeto Folclore.

7 Trabalhamos com essa possibilidade no texto, embora a informação não tenha sido confirmada por laudo médico. 


\section{Referências}

ÀRIES, Philippe. História social da criança e da família. Rio de Janeiro: Francisco Alves, 1979.

GLAT, Rosana. Apresentação. In --- (org.). Educação inclusiva: cultura e cotidiano escolar. Rio de Janeiro: 7Letras, 2009.

DIAS, Vera Lucia et al. "A inclusão do aluno com deficiência auditiva na classe regular: reflexões sobre a prática pedagógica". In GLAT, Rosana (org.). Educação inclusiva: cultura e cotidiano escolar. Rio de Janeiro: 7Letras, 2009.

ESTEBAN, Maria Teresa. Jogos de encaixe: educar ou formatar a pré-escola? In: Revisitando a préescola. GARCIA, Regina Leite (org). São Paulo: Cortez, 1993.

FONTES, Rejane de Souza et al. "Estratégias pedagógicas para a inclusão de alunos com deficiência intelectual no ensino regular". In GLAT, Rosana (org.). Educação inclusiva: cultura e cotidiano escolar. Rio de Janeiro: 7Letras, 2009.

KOHAN, Walter Omar. Infância, estrangeiridade e ignorância - Ensaios de filosofia e educação. Belo Horizonte: Autêntica, 2007.

O mestre inventor: relatos de um educador viajante. Belo Horizonte: Autêntica, 2013.

LUZ, Iza Rodrigues da. Agressividade na primeira infância: um estudo a partir das relações estabelecidas pelas crianças no ambiente familiar e na creche. São Paulo: Cortez, 2008.

QVORTRUP, Jens. Childhood in Europe: a New Field of Social Research. In: CHISHOLM, L. et al. (orgs). Growing Up in Europe - Contemporany Horizons in Childhood and Youth Studies. Berlin, New York: Walter de Gruyter, 1995.

SARMENTO, Manuel Jacinto. As crianças e a infância: definindo conceitos, delimitando o campo. In: SARMENTO, M. J. \& PINTO, M. As crianças e a infância. Braga: UNIMINHO, 1997.

2005.

Crianças: educação, culturas e cidadania activa. In: Perspectiva, Florianópolis, v. 23, p. 17- 40,

Sociologia da infância: correntes e confluências. In: SARMENTO, Manuel Jacinto e GOUVEA, Maria Cristina Soares de (orgs). Estudos da infância: educação e práticas sociais. Petrópolis: Vozes, 2009.

SILVA, Tomaz Tadeu. Teoria cultural e educação: um vocabulário crítico. Belo Horizonte: Autêntica, 2000.

THOMA, Adriana da Silva. O cinema e a flutuação das representações surdas - Que drama se desenrola neste filme? Depende da perspectiva.... Tese (Doutorado em Educação). Programa de PósGraduação em Educação da Universidade Federal do Rio Grande do Sul, Porto Alegre, 2002. 